\title{
Antigen-induced airway hyperresponsiveness and obstruction is related to caveolin-1 expression in airway smooth muscle in a guinea pig asthma model
}

Mayra Álvarez-Santos', Patricia Ramos-Ramírez, Fernando Gutiérrez-Aguilar, Sandra Sánchez-Hernández , Ricardo Lascurain², Raúl Olmos-Zuñiga ${ }^{3}$, Rogelio Jasso-Victoria ${ }^{3}$, Norma A Bobadilla ${ }^{4,5}$ and Blanca Bazan-Perkins ${ }^{*}$

\begin{abstract}
Background: Caveolin-1 is a fundamental signalling scaffold protein involved in contraction; however, the role of caveolin-1 in airway responsiveness remains unclear. We evaluated the relationship between caveolin-1 expression in airway smooth muscle (ASM) and antigen-induced airway responsiveness and obstruction in a guinea pig asthma model.

Methods: Airway obstruction in sensitised guinea pigs, induced by antigenic (ovalbumin) challenges administered every 10 days, was measured. Antigen-induced responsiveness to histamine and the expression of caveolin-1 and cavin 1,2 and 3 were evaluated at the third ovalbumin challenge. The control group received saline solution instead of ovalbumin.

Results: After the first challenge, antigen exposure induced a transient airway obstruction and airway hyperresponsiveness, high levels of IL-4 and IL-5 in lung and airway globet cells proliferation at the third antigenic challenge. Caveolin-1 mRNA levels in total lung decreased in the experimental group compared with controls. Flow cytometric analysis of ASM from the experimental group showed a high number of cells expressing caveolin-1 compared with controls. This increase was confirmed by western blot. Airway obstruction and hyperresponsiveness correlated with the degree of increased caveolin-1 expression in ASM cells $(P<0.05 ; r=0.69$ and -0.52 , respectively). The expression of cavins 1,2 and 3 in ASM also increased in the experimental group compared to controls. Immunohistochemical findings reveal that differences in ASM caveolin-1 were not evident between groups. Nevertheless, a marked decrease in caveolin-1 and caspase 3 was observed in the pulmonary vascular smooth muscle of asthma model compared with controls. Histological analysis did not reveal differences in smooth muscles mass or subepithelial fibrosis levels in airways between groups. However, an enlargement of smooth muscle mass was observed in the pulmonary microvessels of experimental animals. This enlargement did not induce changes in pulmonary or systemic arterial pressures.
\end{abstract}

Conclusions: Our data suggest that caveolin-1 expression in ASM has a crucial role in the development of antigen-induced airway obstruction and hyperresponsiveness in a guinea pig asthma model. In addition, the asthma model in guinea pigs appears to induce a contractile smooth muscle phenotype in the airways and a proliferative smooth muscle phenotype in pulmonary vessels.

Keywords: Airway hyperresponsiveness, Airway obstruction, Airway smooth muscle, Asthma, caspase 3, Caveolin-1, Cavin, Pulmonary arterial smooth muscle

\footnotetext{
*Correspondence: perkins@iner.gob.mx

1 Instituto Nacional de Enfermedades Respiratorias Ismael Cosío Villegas, Departamento de Hiperreactividad Bronquial, Calzada de Tlalpan 4502, Mexico

Full list of author information is available at the end of the article
} 


\section{Background}

Airway smooth muscle is a central structure in asthma pathogenesis. An important characteristic of asthma is that numerous stimuli can trigger intense and rapid bronchospasm in a phenomenon called airway hyperresponsiveness [1,2]. Currently, the precise mechanism by which the development of hyperresponsiveness is induced remains unknown. Nevertheless, airway remodelling features such as fibrosis and smooth muscle hypertrophy/ hyperplasia have been recognised as playing a part [2].

Caveolin-1 is a hairpin-loop protein that forms omegashape invaginations in the plasma membrane, which are known as caveola [3]. In asthma, a shortage of caveolin-1 has been observed in the airways of asthmatic patients [4]. Similar results have been noted in the lungs of ovalbuminchallenged mice, where a reduction of caveolin-1 mRNA expression has been observed [5,6]. In contrast, increased levels of caveolin-1 are found in the airway smooth muscle of antigen-challenged in mice [7] and the lungs of guinea pigs subjected to an asthma model [8].

In airways, caveolin-1 is involved in the downregulation of fibrosis and smooth muscle proliferation $[9,10]$. However, the role of caveolin-1 in airway hyperresponsiveness is unclear. The development of airway hyperresponsiveness in allergen (ovalbumin)-challenged mice without caveolin-1 has been observed [7,11], and Hsia and colleagues [12] have found the absence of caveolin-1 induced airway hyperresponsiveness in endotoxin (lipopolysaccharide)-challenged mice. Moreover, the role of caveolin-1 in airway hyperresponsiveness has become highly controversial due to the view that caveolin-1 is related to the regulation of contractile mechanisms $[9,13,14]$, including, proteins that participate in intracellular $\mathrm{Ca}^{2+}$ mobilisation $[15,16]$. For example, M3 muscarinic, bradykinin, and $\mathrm{H} 1$ histamine receptors and store-operated $\mathrm{Ca}^{2+}$ entry-regulatory mechanisms colocalise with caveolin-1 [17]. Additionally, the recruitment of $\mathrm{Ca}^{2+}$ sensitisation components such as RhoA and PKC $\alpha$ is caveolin-1-dependent $[18,19]$. Furthermore, caveolin-1 is a key regulator of store-operated $\mathrm{Ca}^{2+}$ entry by increasing Orail expression in airway smooth muscle [20].

Since 2005 some proteins named cavins has been associated with caveola biogenesis and organization [21]. In particular, cavin 1 (RNA pol I transcription factor), cavin 2 (serum deprivation protein response) and cavin 3 (SDR- related gene product that binds to $C$ kinase) are widely expressed in tissues, included smooth muscles [22]. Recently, it has been observed a decrease in expression of cavins in airways of caveolin-1 knock-out mice, although its role in airway contraction its unknown [7].

Experimental asthma models are fundamental in asthma research. Particularly, guinea pigs asthma model are susceptible to develop early and late allergic responses after allergen challenge and also can be used as a model for chronic allergic asthma [23,24]. Asthma model in guinea pig is useful since the lung pharmacology and the response to inflammatory mediators is similar to humans in comparison to rats and mouse [25,26].

In the current study, we determined the relationship between caveolin-1 expression and the pathophysiological characteristics of asthma and found that caveolin-1 expression increases in airway smooth muscle and that this increase is related to antigeninduced obstruction and hyperresponsiveness. In contrast, pulmonary vascular smooth muscle showed low expression of caveolin-1, which was accompanied by smooth muscle cell proliferation.

\section{Methods}

We used outbred male guinea pigs weighing 0.35-0.4 kg from Harlan Mexico (strain HsdPoc:DH). The animals were maintained in our institutional laboratory animal facilities with filtered air conditioned at $21 \pm 1^{\circ} \mathrm{C}$ and 50 $70 \%$ humidity, 12/12-h light/dark cycles, sterilised pellets (2040 Harlan Teklad Guinea Pig Diet) and water available ad libitum. All animals were handled according to protocols approved by the Scientific and Bioethics Committee of the Instituto Nacional de Enfermedades Respiratorias.

\section{Study design}

To determinate the role of caveolin-1 in airway smooth muscle pathophysiology during asthma, ovalbumin sensitised guinea pigs were exposed to three antigenic challenges, each administrated every 10 days (Figure 1 ). During each challenge, the broncho-obstructive index was measured. At the third antigenic challenge, the development of antigen-induced airway hyperresponsiveness was evaluated by performing dose-response curves to histamine before and after an antigenic challenge. Animals were then sacrificed to obtain lung and tracheal samples. In lung samples, caveolin-1 mRNA was measured by RT-PCR. Additionally, changes in the amount of collagen in the airway lamina propria and the extent of airway and pulmonary microvessel smooth muscle layers were analysed via light microscopy. Caveolin-1 expression was examined using immunohistochemistry. Caveolin-1 expression in smooth muscle cells from tracheae was measured by flow cytometry. Tracheal smooth muscle strips were used to evaluate the expression of caveolin-1 and cavins 1, 2 and 3 by western blot. Systemic and pulmonary arterial pressures were measured at the third challenge. Control animals received sham manoeuvres performed with saline solution. 


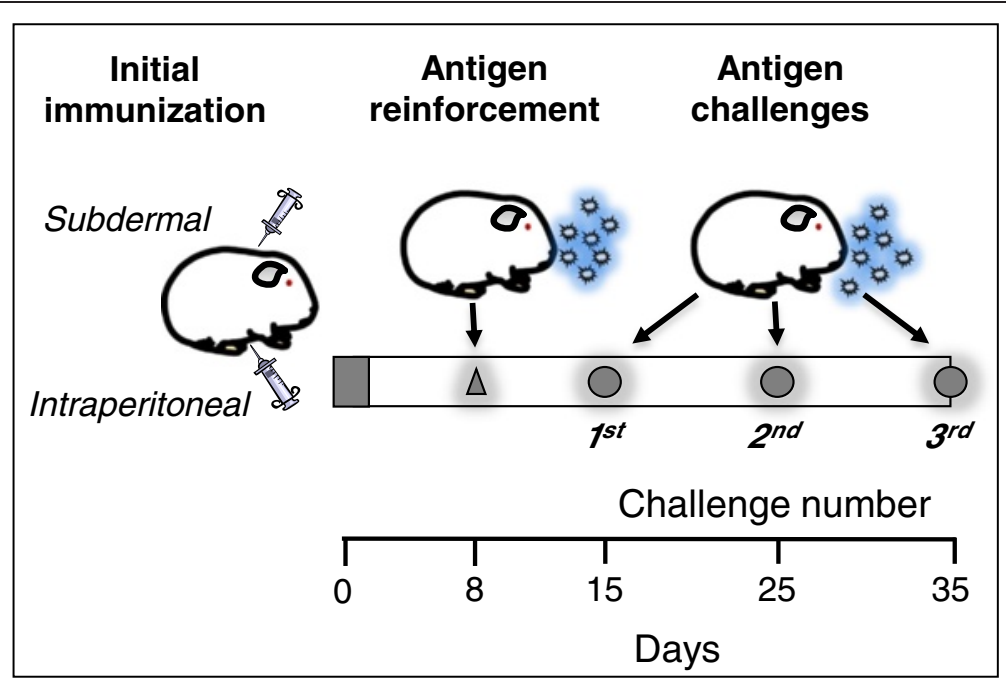

Figure 1 Experimental design. After initial immunisation and reinforcement with antigen (ovalbumin), guinea pigs received three antigen challenges. At third challenge the evaluation of broncho-obstructive index, dose-response curves to histamine as well as immunological, histopathological and vascular function analysis were performed.

\section{Asthma model}

Guinea pigs were sensitised and challenges were performed according to previously described methods $[23,27]$. The antigen sensitisation of guinea pigs was performed by intraperitoneal $(0.5 \mathrm{mg} / \mathrm{ml})$ and subdermal $(0.5 \mathrm{mg} / \mathrm{ml})$ injections with a combination of $60 \mu \mathrm{g} / \mathrm{ml}$ ovalbumin plus $1 \mathrm{mg} / \mathrm{ml}$ aluminium hydroxide dispersed in saline solution (Figure 1). The doses used in sensitisation and challenges in this asthma model were adjusted to reduce anaphylactic shock during challenges. Antigen sensitisation was reinforced eight days later with ovalbumin aerosol ( $3 \mathrm{mg} / \mathrm{ml}$ saline) delivered over five minutes. Aerosols were produced by a US-1 Bennett nebuliser (flow, $2 \mathrm{ml} / \mathrm{min}$; Multistage liquid impinger, Burkard Manufacturing Co., Rickmansworth, Hertfordshire, UK) releasing mixed particles with sizes of $<4 \mu \mathrm{m}$ (44\%), 4-10 $\mu \mathrm{m}$ (38\%), and >10 $\mu \mathrm{m}$ (18\%). From day 15 onward, guinea pigs were challenged over one minute with an ovalbumin aerosol every 10 days $(1 \mathrm{mg} / \mathrm{ml}$ during the first challenge and $0.5 \mathrm{mg} / \mathrm{ml}$ in subsequent challenges) (Figure 1).

Acute airway obstructive responses after ovalbumin inhalation challenges were recorder using a barometric plethysmograph. A whole-body single-chamber plethysmograph for freely moving animals was used (Buxco Electronics Inc., Troy, NY, USA) to evaluate pulmonary function. The signal from the chamber was processed with computer-installed software (Buxco Bio System XA v1.1) to calculate several respiratory parameters, including the broncho-obstructive index, Penh. We calculated this index using the following equation [28]:
Penh $=(($ Te-Rt $) /$ Rt $)$ (PEP/PIP)

where $\mathrm{Te}=$ expiratory time $(\mathrm{s}), \mathrm{Rt}=$ relaxation time $(\mathrm{s})$, $\mathrm{PEP}=$ peak expiratory pressure $\left(\mathrm{cmH}_{2} \mathrm{O}\right)$, and $\mathrm{PIP}=$ peak inspiratory pressure $\left(\mathrm{cmH}_{2} \mathrm{O}\right)$. The software was adjusted to include only breaths with a tidal volume of 1 millilitre or more, with minimal inspiratory time of $0.15 \mathrm{sec}$ onds, maximal inspiratory time of 3 seconds, and maximal difference between inspiratory and expiratory volumes of $10 \%$. This guinea pig model of allergic asthma does not develop a noticeable late airway response. We corroborated that this sensitisation procedure induces the increment of Th2 (CD4 + IL13+) lymphocytes in bronchoalveolar lavage.

\section{Antigen-induced airway responsiveness}

In guinea pigs, airway hyperresponsiveness was measured after antigen challenge in sensitised $(n=18$; asthma model) and non-sensitised $(n=13$; control group) animals [27]. Airway responsiveness was evaluated on day 35 (third ovalbumin challenge) by exposing each animal to increasing non-cumulative doses of histamine aerosols (0.001 to $0.32 \mathrm{mg} / \mathrm{ml}$; Sigma Chemical Co., St. Louis, MO, US) after an initial bronchoobstructive index acquisition before and after ovalbumin administration. Each histamine dose was delivered over 1 minute, and the average of the broncho-obstructive index over the following $10 \mathrm{~min}$ was obtained. The interval between doses was $10 \mathrm{~min}$. The dose-response curve finished when the broncho-obstructive index reached three times its baseline level. Once the index returned to the initial baseline value ( $<50 \%$ increment), the ovalbumin challenge was administered. A second curve was measured 
three hours later. Control group received saline instead ovalbumin administration.

\section{Dissection of airway smooth muscle strips for flow cytometry and Western blot studies}

Twenty-four hours after concluding histamine curves, some sensitised $(n=10)$ and non-sensitised $(n=9)$ guinea pigs were overdosed with an intraperitoneal injection of pentobarbital sodium $(65 \mathrm{mg} / \mathrm{kg})$, and their tracheae were dissected to obtain airway smooth muscle strips.

\section{Isolation of airway smooth muscle cells}

The strips of 7 sensitised and 6 non-sensitised guinea pigs were incubated at $37^{\circ} \mathrm{C}$ for $10 \mathrm{~min}$ in $5 \mathrm{ml}$ of Hanks' solution (Gibco, Gaithersburg, MD, US) with $2 \mathrm{mg}$ cysteine and $0.05 \mathrm{U} / \mathrm{ml}$ papain (Sigma Chemical Co., St. Louis, MO, US). The strips were then washed in Leibovitz's solution (Gibco, Gaithersburg, MD, US) and placed in a physiological saline solution (PSS, $\mathrm{mM}$ ) containing 118 $\mathrm{NaCl}, 25 \mathrm{NaHCO}_{3}, 4.6 \mathrm{KCl}, 1.2 \mathrm{MgSO}_{4}, 1.2 \mathrm{KH}_{2} \mathrm{PO}_{4}$ and 11 glucose (Sigma Chemical Co., St. Louis, MO, US). Smooth muscle strips were cut $(0.5 \times 5 \mathrm{~mm})$, and fragments weighing $200 \mathrm{mg}$ total were placed in $2.5 \mathrm{ml}$ PSS with collagenase type I $(1 \mathrm{mg} / \mathrm{ml}$; Sigma Chemical Co., US) and dispase II ( $4 \mathrm{mg} / \mathrm{ml}$; Sigma Chemical Co., St. Louis, MO, US) at $37^{\circ} \mathrm{C}$. Ten minutes later, the fragments were transferred to similar PSS containing fresh enzymes. Tissue was dispersed mechanically until isolated cells were observed. Leibovitz's solution was added to stop the enzymatic activity.

\section{Flow cytometry}

For the detection of caveolin-1 production in the isolated airway smooth muscle cells, a three-color immunofluorescence approach was used following a previously described method [29]. Isolated myocytes were incubated with $10 \mu \mathrm{g} / \mathrm{ml}$ brefeldin-A (Sigma Chemical Co.; St. Louis, MO, US) for four hours to inhibit new cytokine release. After staining, cells were washed, fixed with $4 \%$ p-formaldehyde for $10 \mathrm{~min}$ at $4^{\circ} \mathrm{C}$, washed, and permeabilised with $0.1 \%$ saponin in PBS with $10 \%$ BSA and $1 \% \mathrm{NaN}_{3}$. Afterwards, cells were gently shaken in the dark for $15 \mathrm{~min}$ at room temperature and $1 \mu \mathrm{l} / 1 \times 10^{6}$ cells were labelled with caveolin-1 antibody (BD Biosciences Pharmingen, San Diego, CA, US). Then, cells were incubated during $30 \mathrm{~min}$ with secondary antibody FITC mouse (BD Biosciences Pharmingen, San Diego, CA, US). Finally, cells were analysed for the expression of markers, on a FACScan flow cytometer (Becton Dickinson, San Diego, CA, US) using software, and 10,000 events were counted. To analyse the staining of intracellular caveolin1 , the blasts were initially gated by their physical properties (forward and side scatter). A second gate was then drawn based on the fluorescence characteristics of the gated cells, assessing fluorescence intensity by histograms. Intensity of fluorescence staining is expressed as the mean fluorescence intensity. Control stains were performed using fluorochrome-conjugated isotype-matched antibodies. Background staining was $<1 \%$ and subtracted from experimental values.

\section{Western blot analysis}

Smooth muscle strips from guinea pig tracheae $(n=3$, each group) were placed in lysis buffer ( $1 \%$ Triton X100, 50 mM Tris, pH 7.4, $150 \mathrm{mM} \mathrm{NaCl}, 0.1 \mathrm{mM}$ EDTA and EGTA, $1.0 \mathrm{mM}$ phenylmethylsulfonyl fluoride, $10 \mu \mathrm{g} / \mathrm{ml}$ aprotinin and leupeptin, $1.0 \mathrm{mM} \mathrm{Na}_{3} \mathrm{VO}_{4}$, and 50 mM NaF; Sigma Chemical Co.; St. Louis, MO, US) and homogenised (Polytron PT3100, Kinematica, Switzerland). Tissue protein $(40 \mu \mathrm{g})$ from each sample was loaded in different lanes of a 12\% SDS-polyacrylamide gel. In an additional lane, a control protein (GAPDH; Sigma Chemical Co.; US) was also added. After electrophoretic separation under reducing conditions, proteins were transferred to a nitrocellulose membrane and quenched with Tris-buffered saline (TBS) containing 5\% non-fat milk and $0.1 \%$ Tween-20. Membranes were subjected to overnight incubation $\left(12 \mathrm{~h}, 4^{\circ} \mathrm{C}\right)$ with rabbit polyclonal antibodies raised against caveolin-1 (BD Biosciences Pharmingen, San Diego CA, US), cavin-1 (Anti/PTRF/ Cavin-1, Millipore, Billerica MA, USA), cavin-2 (SDR, Thermo Scientific, Rockford IL, USA) and cavin-3 (PRKCDBP, Thermo Scientific, Rockford IL, USA), and then washed three times with TBS-Tween-20 (0.1\%). Caveolin and cavins were detected by adding horseradish peroxidase-labelled anti-mouse antibodies. Immunoblots were developed using an enhanced chemiluminescent reactant (LumiGLO, Cell Signalling; US) and an optimal exposition of the nitrocellulose sheets to X-ray films (Biomax ML Film, Kodak, Rochester, NY US). Caveolin-1 and cavin immunoblots were analysed by densitometry using Kodak digital science ID software version 2.03 (Eastman Kodak, Rochester, NY, US).

\section{RNA isolation}

Total RNA from the right lung of some sensitised and non-sensitised ( $n=3$, each group) guinea pigs was isolated following the guanidine isothiocyanate-caesium chloride method [30]. Total RNA was examined by $1 \%$ agarose gel electrophoresis, and the RNA concentration was determined by UV light absorbance at $260 \mathrm{~nm}$ to evaluate the integrity of RNA (Beckman DU640, Fullerton, CA, US).

\section{RT-PCR}

The relative level of caveolin-1 mRNA expression was assessed in left lung homogenates by semiquantitative 
RT-PCR, as previously described [31]. Briefly, all primer sequences were custom ordered from GIBCO BRL (Gaithersburg, MD, US). Sense caveolin-1 primers were amplified to obtain a fragment of $230 \mathrm{bp}$, bases 1 to 230 (sense $5^{\prime}$-ATG TCT GGG GGT AAA TAC GT-3' and antisense: 5'-CCT TCT GGT TCC GCA ATC AC-3). A fragment of GAPDH was also amplified to evaluate or reduce nonspecific effects of experimental treatment and to semi-quantify caveolin1 expression. RNA samples were treated with DNAse to evaluate genomic DNA contamination relative to samples passed through a PCR procedure without adding reverse transcriptase. RT-PCR was carried out using $2.5 \mu \mathrm{g}$ of total RNA from lung homogenate. Before the RT-PCR reaction, total RNA was heated at $65^{\circ}$ $\mathrm{C}$ for $10 \mathrm{~min}$. RT-PCR was performed at $37^{\circ} \mathrm{C}$ for $60 \mathrm{~min}$ in a total volume of $20 \mu \mathrm{l}$ using $200 \mathrm{U}$ of the Moloney murine leukaemia virus reverse transcriptase (GIBCO BRL, Gaithersburg, MD, US), 100 pM of random hexamers (GIBCO, BRL Gaithersburg, MD, US), $0.5 \mathrm{mM}$ of each dNTP (Sigma, St. Louis, MO, US), and $1 \times$ RT buffer $(75 \mathrm{mM} \mathrm{KCl}, 50 \mathrm{mM}$ Tris $\cdot \mathrm{HCl}$, $3 \mathrm{mM} \mathrm{MgCl} 2,10 \mathrm{mM} \mathrm{DTT}, \mathrm{pH}$ 8.3). Samples were heated at $95^{\circ} \mathrm{C}$ for $5 \mathrm{~min}$ to inactivate the reverse transcriptase and diluted to $40 \mu \mathrm{l}$ with PCR-grade water. One-tenth of RT-PCR individual samples from each group was used for caveolin-1 or GAPDH amplification in $20-\mu$ final volume reactions containing $1 \times$ PCR buffer $(10 \mathrm{mM}$ Tris $\cdot \mathrm{HCl}, 1.5 \mathrm{mM} \mathrm{MgCl} 2,50 \mathrm{mM}$ $\mathrm{KCl}, \mathrm{pH} 8.3), 0.1 \mathrm{mM}$ of each dNTP, $0.2 \mu \mathrm{Ci}$ of

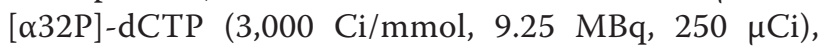
$10 \mu \mathrm{M}$ of each primer, and one unit of Taq DNA polymerase (GIBCO, BRL Gaithersburg, MD, US). Samples were overlaid with $30 \mu \mathrm{l}$ of mineral oil and PCR cycles were performed in a DNA thermal cycler (M.J. Research, Watertown, MA, US), with the following profile: denaturation for $1 \mathrm{~min}$ at $94^{\circ} \mathrm{C}$; annealing for $1 \mathrm{~min}$ at $55^{\circ} \mathrm{C}$ and a 1 -min extension step at $72^{\circ} \mathrm{C}$. The last cycle was followed by a final extension step of $5 \mathrm{~min}$ at $72^{\circ} \mathrm{C}$. Control gene was co-amplified simultaneously in each reaction. Amplification kinetics were performed following our standard procedure [31]. To analyse PCR products, onehalf of each reaction was electrophoresed in a $5 \%$ acrylamide gel. Bands were stained with ethidium bromide, visualised under UV light, cut out, suspended in $1 \mathrm{ml}$ of scintillation cocktail (Ecolume, ICN, Aurora, OH, US), and counted by liquid scintillation (Beckman LS6500, Fullerton, CA, US). The amount of radioactivity recovered from the excised bands was plotted in a $\log$ scale against the number of cycles. To semi-quantify caveolin-1 and the control gene, all reactions were performed at least in quadruplicate.

\section{Conventional histology and automated morphometry analysis}

Left caudal lung lobes of some guinea pigs $(n=6$, each group) were dissected and fixed by manual perfusion of $10 \%$ neutral buffered formaldehyde solution via intraarterial route until the lung lobe was exsanguinated. Lung fragments obtained by sagittal cutting were embedded in paraffin, and $4 \mu \mathrm{m}$-thick lung sections were stained with Masson trichrome stain. The surface areas $\left(\mu \mathrm{m}^{2}\right)$ of airway smooth muscle and lamina propria, as well as the vascular smooth muscle of adjacent vessels, were determined through the use of automated morphometry (Qwin, Leica Microsystems Imaging Solutions, Cambridge, UK). Data were adjusted by length of the corresponding basement membrane, and their average was considered the final result. All measurements were conducted in six bronchi, six bronchioles and six arterioles $(\sim 100 \mu \mathrm{m}$ diameter $)$ chosen randomly from each animal. Total epithelial cells in six bronchi of each guinea pig were counted and the percentage of globet cell was obtained. The bronchus and bronchiole were identified by the presence or absence of cartilage in the airway wall, respectively.

\section{ELISA}

Anti-human interferon- $\gamma$ (IFN- $\gamma$; R\&D System, Minneapolis, USA), interleukin-4 (IL-4; R\&D System, Minneapolis, USA) and IL-5 (clone TRFK5; BD Pharmingen, USA), antibodies were used in lung homogenates of sensitized and non sensitised guinea pigs ( $n=6$, each group) to measure cytokines by ELISA as previously described [27].

\section{Immunohistochemistry and immunofluorescence}

The same paraffin-embedded lung tissue blocks used for the morphometric study were used for immunohistochemistry ( $n=6$, each group) and immunofluorescence $(n=2$, each group). Sections $(3 \mu \mathrm{m})$ were deparaffinised $\left(55^{\circ} \mathrm{C}, 30 \mathrm{~min}\right)$ and rehydrated through submersion in graded alcohols (xylene, 1:1 xylene-alcohol, alcohol, and $70 \%$ alcohol for $10 \mathrm{~min}$ each, followed by rinsing in distilled water). Antigen retrieval was performed with $10 \mathrm{mM}$ citrate buffer, $\mathrm{pH} 6$, for $5 \mathrm{~min}$ in a microwave oven. Samples were treated with hydrogen peroxide (3\%) to quench endogenous peroxidase, and nonspecific sites were blocked later with horse serum (2\%). Sections were incubated at $4{ }^{\circ} \mathrm{C}$ overnight with an antibody to caveolin1 (BD Biosciences Pharmingen, San Diego CA, US). To detect the specific binding of this primary antibody, an R.T.U. Vectastain Universal Quick Kit was used (Vector Laboratories, Inc., Burlingame, CA, USA) in which tissues were incubated sequentially with blocking serum, a panspecific secondary antibody, and streptavidin/peroxidase complex. Finally, 3-amino-9-ethyl-carbazole (BioGenex, 
A)

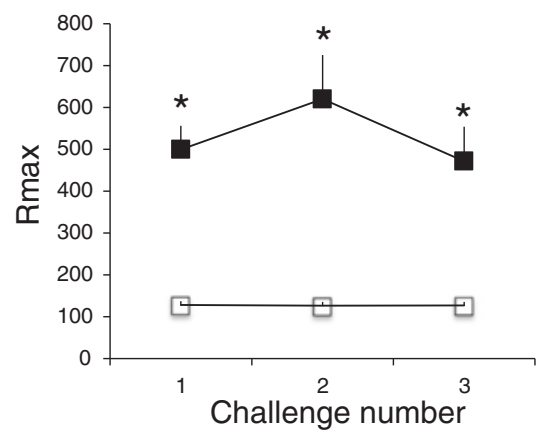

B)

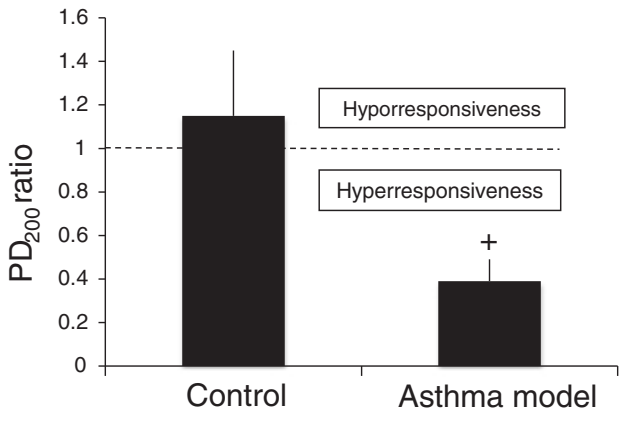

Figure 2 Antigen-induced airway obstruction and responsiveness in sensitised guinea pigs. A) Average of maximum broncho-obstructive index (Rmax) induced by ovalbumin (closed squares) and saline (open squares) challenges in sensitised guinea pigs. B) $\mathrm{PD}_{200}$ ratio corresponds to $\mathrm{PD}_{200}$ value observed after antigen challenge divided by $\mathrm{PD}_{200}$ value before challenge. Bars represent mean $\pm \mathrm{SEM}$ ( $n=7$ per group). ${ }^{*} P<0.05$ compared with contro (repeated measures ANOVA with Dunnett's multiple comparisons test). ${ }^{+} P<0.05$ compared with control (unpaired Student's $t$-test).

San Ramon, CA, USA) was used as a chromogen. Sections were counterstained with Mayer's haematoxylin. Slides were rinsed twice with $0.1 \%$ Tween-20 phosphatebuffered saline during the whole process. To control for the non-specific binding of the secondary antibody, sections from the same lung were processed without the primary antibody. No positive staining was observed in non-specific binding controls. The rabbit IgG (Southern Biotech, Birmingham, AL, USA) isotype control was negative.

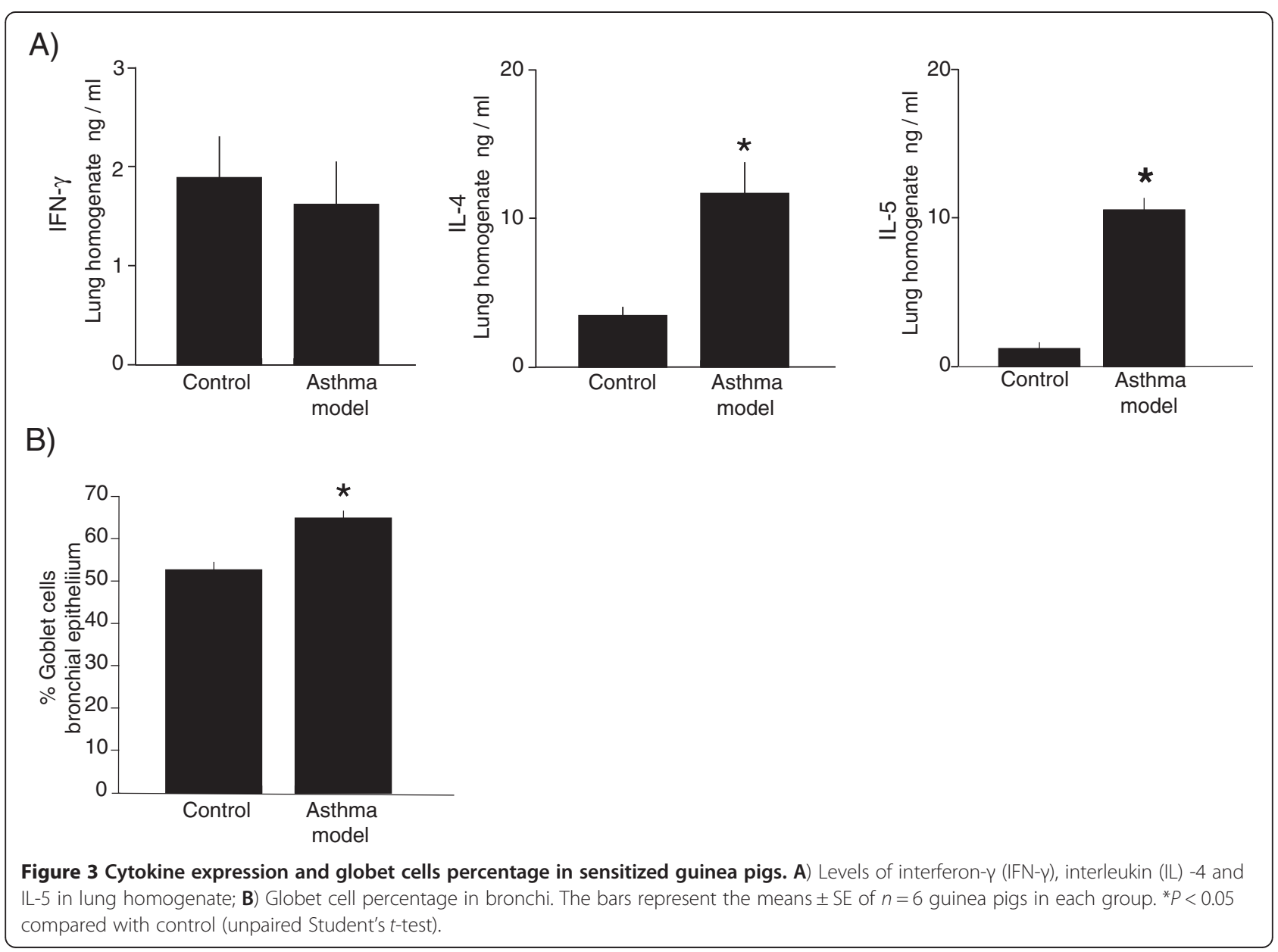




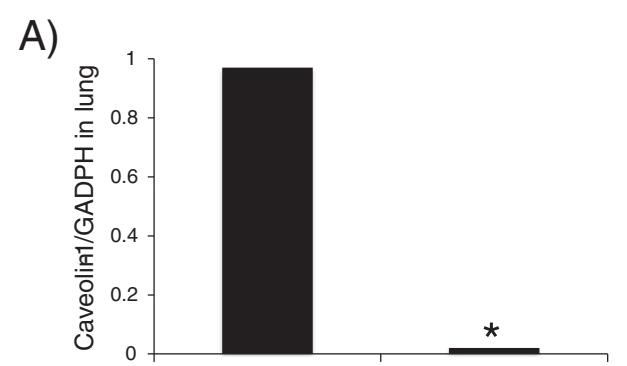

B)

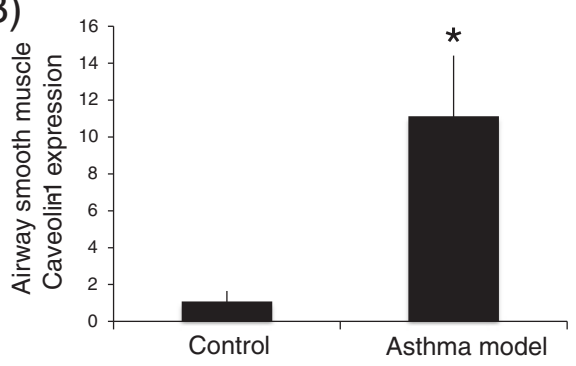

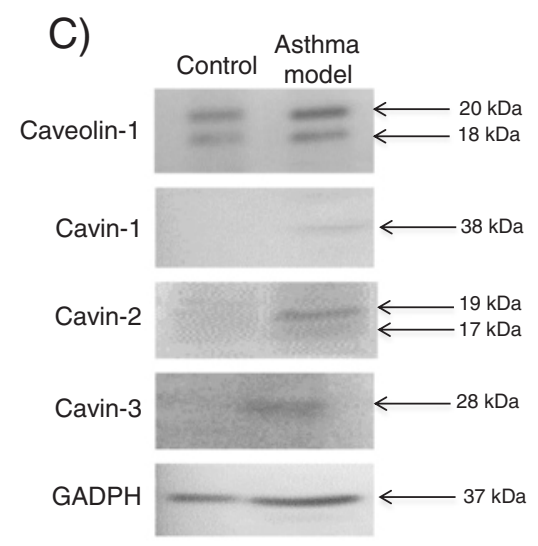

Figure 4 Caveolin-1 expression in airway smooth muscle. A) Caveolin-1 mRNA levels in lung ( $n=3$ in all groups). B) Caveolin- 1 expression in tracheal isolated airway myocytes, measured by flow cytometry ( $n=6,7$ for control and asthma model groups). C) Representative autoradiographs of caveolin-1 and cavins-1, 2 and 3 by western blot in tracheal airway smooth muscle ( $n=3$ in all groups). Bars represent mean \pm SEM. ${ }^{*} P<0.01$ compared with control (unpaired Student's t-test).

For the detection of caspase 3 by immunofluorescence, paraffin-embedded tissue was cut 4-6 m thick and tissue sections were placed in slides and incubated for $30 \mathrm{~min}$ at $55^{\circ} \mathrm{C}$. Tissue slides were deparaffinized in xylenes twice for $10 \mathrm{~min}$ each. Hydrate sections gradually through graded alcohols using 2 changes for 10 min each of the following solutions: $100 \%$ ethanol, 95\% ethanol, and deionized water. For antigen unmasking, slides were covered with $10 \mathrm{mM}$ sodium citrate buffer, $\mathrm{pH} 6.0$, and heat at $95^{\circ} \mathrm{C}$ for $5 \mathrm{~min}$. Slides were then cooled in TBS-T buffer for $20 \mathrm{~min}$ at room temperature. To suppress non-specific binding of antibodies, tissue slides were incubated with $0.2 \%$ BSA in PBS for $20 \mathrm{~min}$ at $4^{\circ} \mathrm{C}$. After that, immunofluorescence staining was carried out by overlaying each slide with $20 \mu \mathrm{l}$ of rabbit polyclonal anti-caspase 3 antibody (Abcam, San Francisco, CA, USA) for $2 \mathrm{~h}$ at $4^{\circ} \mathrm{C}$. After washing in TBS-T buffer for $5 \mathrm{~min}$, a secondary incubation was performed with fluorescein isothiocyanate (FITC)-labeled goat anti-rabbit IgG (Jackson ImmunoResearch Laboratories Inc. Amish Country, PA, USA) for $30 \mathrm{~min}$ at $4^{\circ} \mathrm{C}$. After twice washing, slides were counterstained with fluoroshield mounting medium with DAPI (Sigma-Aldrich Co, St. Louis, MO, USA) for nuclei staining (blue channel). All incubations were carried out in a humidified dark chamber. In other experiments, tissue slides were incubated only with FITC-labeled secondary antibody, which was used as background staining control. Finally, tissue slides were examined by fluorescence microscope with appropriate filters (Leica DM-LS 2000, Mannheim, Germany), and analyzed by ImageJ64 software (http:// rsb.info.nih.gov/ij/).

\section{Hemodynamic}

After $12 \mathrm{~h}$ of fasting, some guinea pigs ( $n=8$ for sensitised, and $n=4$ for non-sensitised) were anaesthetised with isofluorane (1.5\%, Sofloran, México, DF) delivered by a precision vaporiser (Isotec 3, Ohmeda, Steeton, West Yorkshire, UK) carried in oxygen. Their heart rates were monitored with an automatic non-invasive device Datascope Passport Model EL (Datascope Corp, Mahwah, NJ, USA), and after deep anaesthesia, animals were ventilated through a trachea cannula that was connected to both, a ventilator (Harvard, Rodent Model Ventilator 683) and the vaporiser. Then, the right carotid artery was dissected, and a catheter was introduced to measure the systemic arterial pressure and diastolic arterial pressure. A similar procedure was performed to introduce a catheter into the pulmonary artery through the right ventricle to determine the pulmonary arterial pressure. Datascope Passport monitored all pressures.

\section{Materials}

Ovalbumin (chicken egg albumin) grade II and all stains for microscopy were purchased from Sigma Chemical Co. (US). Aluminium hydroxide was purchased from J.T. Baker, USA. Pentobarbital sodium was acquired from Pfizer, Mexico. 


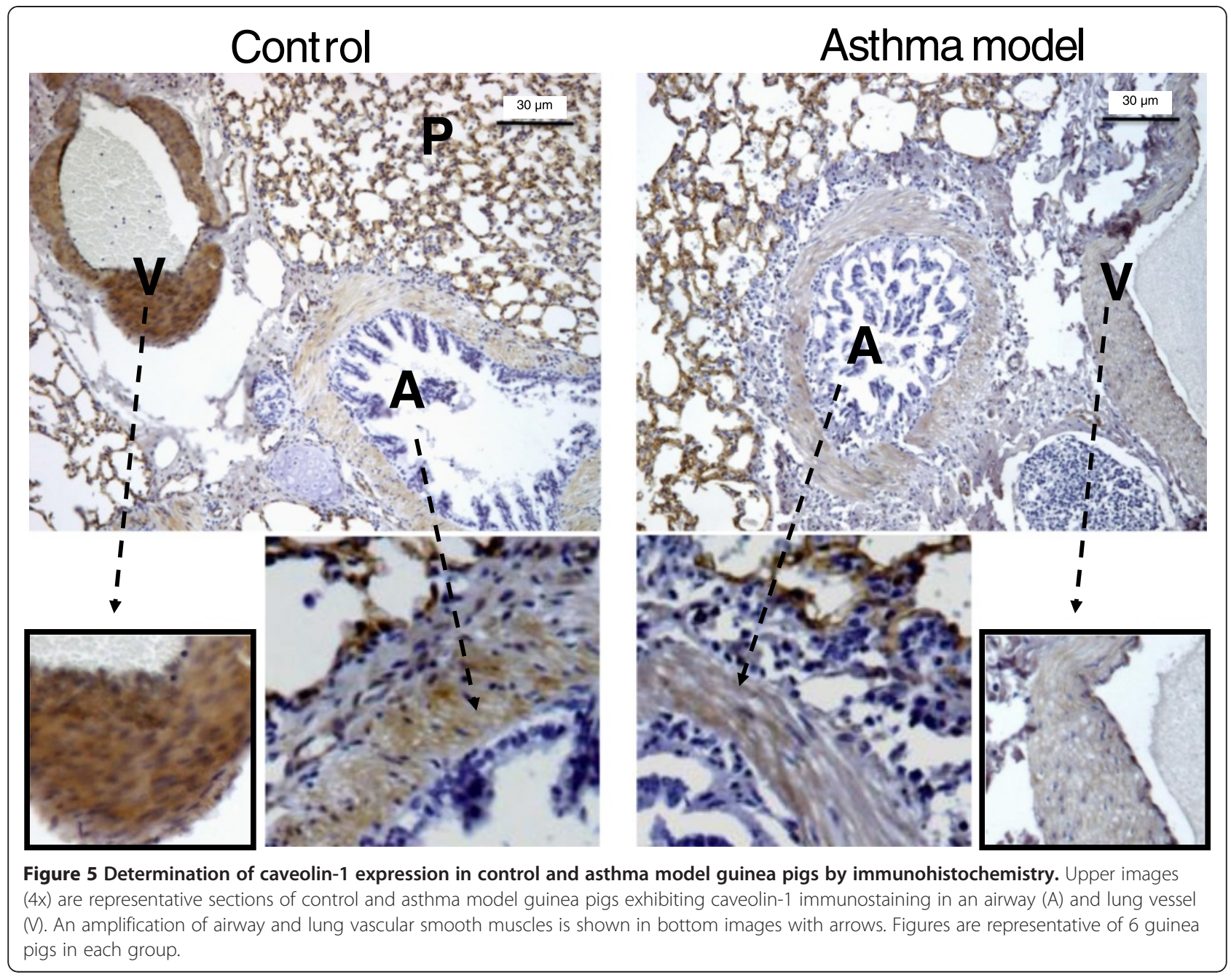

\section{Statistical analysis}

Airway responsiveness to histamine was evaluated by means of the provocative dose $200 \%\left(\mathrm{PD}_{200}\right)$, i.e., the interpolated histamine dose that caused a three-fold increase of basal broncho-obstructive index. Change in histamine responsiveness induced by antigen challenge was evaluated by the $\mathrm{PD}_{200}$ ratio, i.e., $\mathrm{PD}_{200}$ value observed after OVA challenge divided by $\mathrm{PD}_{200}$ value before challenge. In multiple comparisons, one-way or repeated-measure ANOVA followed by Dunnett's tests was used. Comparison between control and asthma model groups was evaluated by means of Student's unpaired $t$-test. Associations between caveolin-1 and airway responsiveness and obstruction were assessed through Spearman's correlation coefficient. Statistical significance was set at two-tailed $P<0.05$. Data in the text and figures are expressed as the mean \pm SEM.

\section{Results and discussion}

Antigen-induced airway obstruction and responsiveness The guinea pig has served as a helpful model in the study of asthma, with some advantages over other models such as the rat and mouse, because it shares various pharmacological characteristics of human asthma, besides the strong airway obstructive response that guinea pigs exhibit after agonist stimulation [32]. Responses to antigen challenge in guinea pig asthma models are characterised by a rapid and transient airway obstruction in sensitised animals [23,27]. In the current study, the values of basal airway obstruction index were similar between control and experimental groups (data not shown). Saline challenge did not modify the basal obstruction index in the control group, but ovalbumin challenge induced a transient increase in the index that reached statistical significance in comparison with the control group $(P<0.05 ; n=18$ asthma model, and $n=13$ control group; Figure 2A).

An important pathophysiological feature of asthma is the development of airway hyperresponsiveness. In this study, the basal histamine $\mathrm{PD}_{200}$ value was similar between the control and experimental groups (data not shown). In the control group, the histamine $\mathrm{PD}_{200}$ value after saline challenge was similar to the basal $\mathrm{PD}_{200}$ 
value. In the experimental group, the $\mathrm{PD}_{200}$ value after ovalbumin challenge was lower than the basal $\mathrm{PD}_{200}$ value. In the control group, the $\mathrm{PD}_{200}$ ratio was significantly lower than that obtained in the control group $(P<$ $0.05 ; n=18$ asthma model, and $n=13$ control group; Figure $2 \mathrm{~B}$ ), implying that all guinea pigs sensitised with the antigen showed hyperresponsiveness to histamine.

Inflammatory markers in asthma as the Th2 cytokines IL-4 and IL-5 [33] significantly increases in lung homogenates of asthma model guinea pigs in comparison with controls $(P<0.05 ; n=6$ each group; Figure $3 \mathrm{~A})$. In contrast IFN- $\gamma$, a Th1 cytokine, has similar levels in both groups (Figure 3A). In addition, a significantly increment of globet cells was observed in bronchi epithelium of asthma model group $(\mathrm{P}<0.05 ; n=6$ each group; Figure $3 \mathrm{~B})$ suggesting that this model of acute asthma induces structural changes in airway epithelium.

\section{Caveolin-1 expression in asthma model}

In comparison with other cells, smooth muscle expresses high levels of caveolin-1 in the plasma membrane [34]. In airway smooth muscle, the signalling platform associated with caveolin- 1 takes important roles in the recruitment of various signalling proteins involved in contraction. For example, caveolin-1 is involved in $\mathrm{Ca}^{2+}$ homeostasis via the presence of voltage gated L-type $\mathrm{Ca}^{2+}$ channels, the plasma membrane $\mathrm{Ca}^{2+}$ ATPase, calsequestrin and calreticulin in caveolin-enriched membranes [15]. Other components that play a role in airway smooth muscle contraction, such as M3 muscarinic, bradykinin, H1 histamine, phospholipase $\mathrm{C} \beta 1$, Goq and store-operated $\mathrm{Ca}^{2+}$ entry-regulatory mechanisms, co-localise with caveolin-1 [17,35]. Moreover, TNF$\alpha$, a fundamental cytokine in asthma pathogenesis [36], induces RhoA activation, enhances force responses to acetylcholine, and increases $\mathrm{Ca}^{2+}$ responses to acetylcholine, histamine and bradykinin through caveolin-1 upregulation $[18,37,38]$. Certainly, caveolin-1 is associated with key molecules that participate in airway smooth muscle contraction.

In agreement with other studies [4-6], we found that caveolin-1 is downregulated in the lung homogenates of experimental animals, as shown in Figure 4A. The level of caveolin-1 mRNA in the lung homogenate of controls was significantly higher in comparison to the experimental group $(P<0.01 ; n=3$ in all groups); nevertheless, flow cytometric studies in isolated myocytes demonstrated that the number of cells that express caveolin-1 increased significantly in the experimental group compared to controls $(P<0.01 ; n=6$ and 7 for control and asthma model groups, respectively; Figure 4B). Similar results in the airway smooth muscle bundles of experimental group animals obtained by immunohistochemistry analysis have been described previously [8]. In our study, we observed that functional changes in the asthma model correlated with the number of smooth muscle cells that expressed caveolin-1. The $\mathrm{PD}_{200}$ ratio
A)

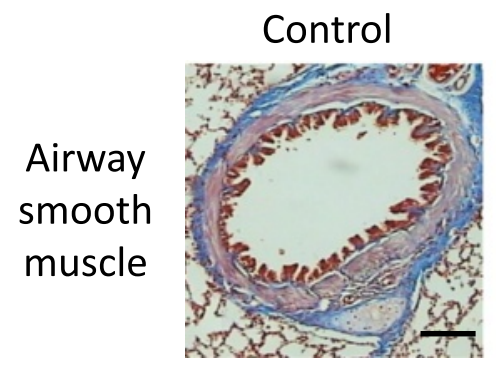

B)

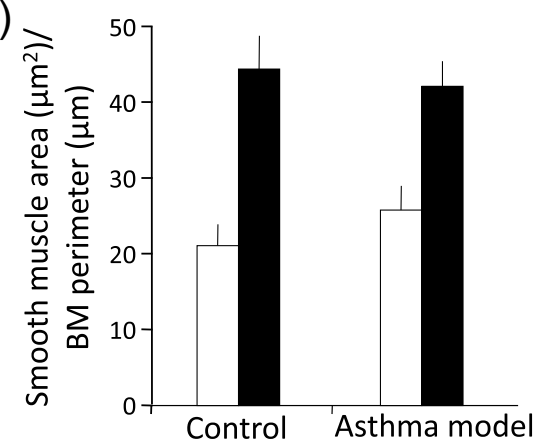

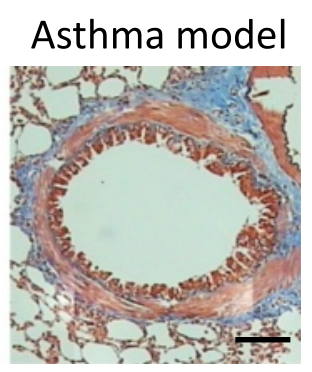

C)

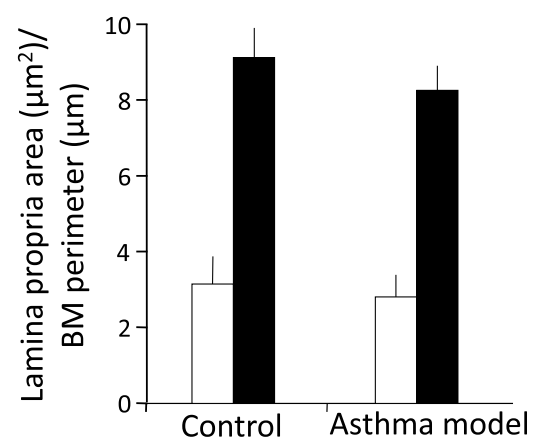

Figure 6 Representative histological features of airway in a guinea pig allergic asthma model. A) Low-power micrograph (10x) from the lungs of control and experimental guinea pigs showing bronchi. B) Area of smooth muscle layer and C) lamina propria of bronchioles (white bars) and bronchi (black bars), adjusted by the basement membrane (BM) perimeter, as measured by automated morphometry. Bars and vertical lines are mean \pm SE of $n=6$ per group. ${ }^{*} P<0.01$ (unpaired Student's $t$-test). 


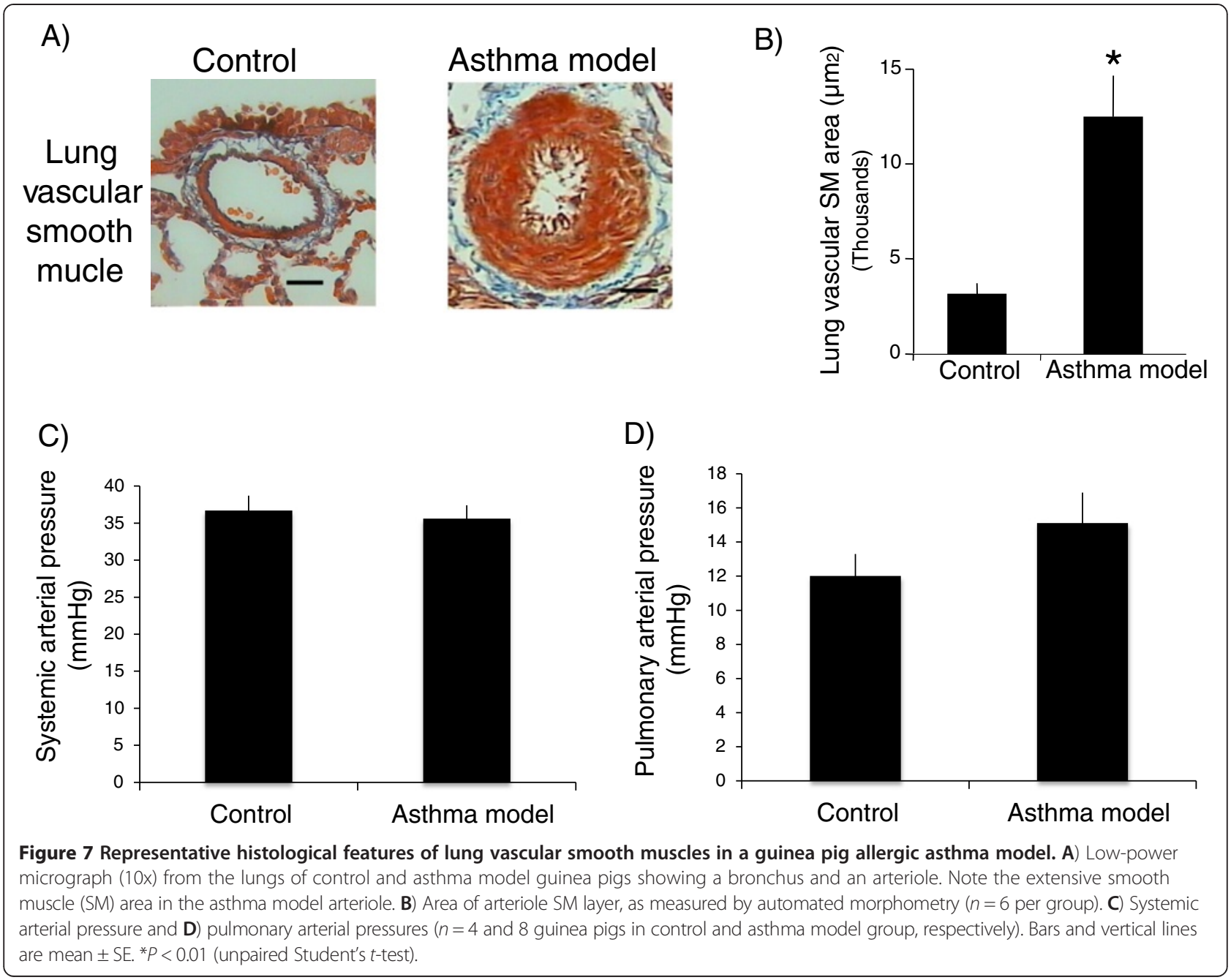

was inversely correlated with airway smooth muscle caveolin-1 ( $\mathrm{r}=-0.517, P<0.05 ; n=13)$, implying that a greater number of cells positive for caveolin-1 corresponded to greater antigen-induced airway responsiveness. In addition, the Rmax correlated with the number of cells positive for caveolin-1 $(r=0.691, P<0.01 ; n=13)$, indicating that antigen-induced airway obstruction is directly associated with caveolin-1 in airway smooth muscle cells.

Western blot analysis detected two specific bands for caveolin-1 at approximately 18 to $20 \mathrm{kDa}$, and the expression of both bands increased in the experimental group (Figure $4 \mathrm{C} ; n=3$ all groups). In addition, cavins 1 , 2 and 3, a group of proteins that, along with caveolin-1, regulates caveolae organisation and function [3], were found in controls but were more highly expressed in the experimental group (Figure $4 C ; n=3$ in all groups). Previously, cavins 1,2 and 3 have been found to increase in the airway smooth muscle of ovalbumin-sensitised mice [7]. Although the role of cavins in asthma is unknown, TNF- $\alpha$ induced the upregulation of cavins in airway smooth muscle, suggesting that inflammation may regulate cavin expression [39].

Immunohistochemical images did not reveal noticeable changes in caveolin-1 staining between controls and asthma model groups in airway smooth muscle or parenchyma (Figure $5 ; n=6$ all groups); nevertheless a strong reduction of caveolin-1 expression in vascular smooth muscle of the experimental group was observed in comparison with controls (Figure 5). In view that only pulmonary vascular smooth muscle showed a strong reduction in caveolin-1 expression in asthma model, and the other structures did not exhibit changes, it is possible that the intense decrease in caveolin-1 mRNA levels in total lung homogenates (Figure 4A) of the asthma model was likely produced by the downregulation of caveolin-1 in this smooth muscle.

\section{Airway and lung vascular smooth muscle structure}

Airway remodelling has been proposed as an important factor associated with caveolin in the development of 
airway hyperresponsiveness. For example, in a previous study [23] of a model of chronic asthma in guinea pigs (nine antigen challenges), we found an association between subepithelial fibrosis and airway hyperresponsiveness. Caveolin-1 contributes to remodelling by producing suppressive effects in airway smooth muscle proliferation [9], likely through the inhibition of constitutive p42/p44 MAPK activity [40] and by inducing type I collagen in lung tissue [5]. Airway hyperresponsiveness is a consequence of airway remodelling induced by the lack of caveolin-1 in knock-out mice [7,11].

To evaluate airway remodelling in guinea pigs, Masson trichrome staining was used to distinguish airway and lung vascular smooth muscle layers based on their strong red cytoplasmic staining (Figures 6A and 7A). Automated morphometric analysis of smooth muscle mass and subepithelial fibrosis of bronchioles and bronchi did not show significant differences between control and asthma models (Figure 6B and $C ; n=6$ in control and $n=7$ in asthma model groups). In addition, we did not observe an association between the degree of hyperresponsiveness and the level of subepithelial fibrosis $(r=0.25 ; n=13)$ or airway smooth muscle mass $(r=0.18 ; n=13)$. Nevertheless, widening of the airway adjacent vessels was observed $(P<0.05 ; n=6$ per group; Figure $7 \mathrm{~A}$ and $\mathrm{B})$. The total numbers of smooth muscle nuclei in bronchioles in the experimental and control groups were similar $(29 \pm 2.3$ and $28 \pm 2.5$ nuclei, respectively; $n=6$ per group, data

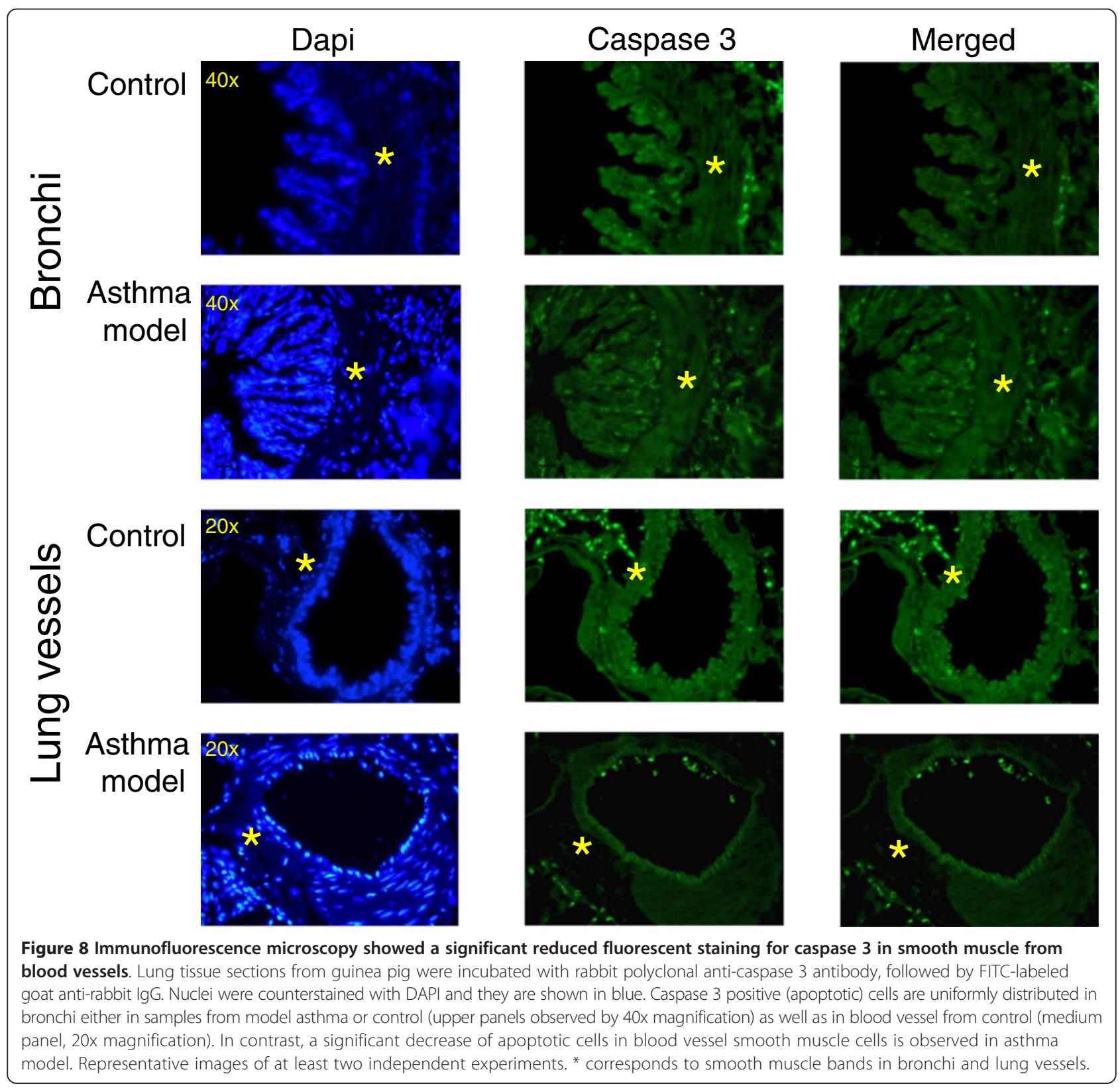


not illustrated); however, an increase in the number of total smooth muscle cell nuclei from airway adjacent vessels was observed in experimental guinea pigs compared with controls $(51 \pm 10.4$ and $12 \pm 1.2$ nuclei, respectively; $P<0.01 ; n=6$ per group, data not shown). In addition, caspase 3 expression determinate by immunofluorescence in bronchi smooth muscle did not show noticeable change in asthma model and control groups; nevertheless, an evident diminution of caspase 3 expression was observed in lung smooth muscle from vessels in asthma model group $(n=2$; Figure 8$)$. It suggests that apoptosis is inhibited in vascular smooth muscle in asthma model, a tissue that also shows a decrement of caveolin-1 expression (Figure 5) and an enlargement of tissue area (Figure 7B). According to the above, these findings are in agreement with the antiproliferative and proapoptotic effects induced by caveolin-1 observed in almost cell types [41]. Then, in conclusion these results suggest that pulmonary vascular smooth muscle, but not airway smooth muscle, is capable to show remodelling changes in acute asthma model in guinea pigs and that caveolin-1 is associated with this phenomenom.

\section{Arterial pressure in asthma model}

A feature of the contractile, but not proliferative, airway smooth muscle phenotype is the abundance of caveolae, suggesting that caveolin-1 may have an inhibitory role in airway smooth muscle proliferation [9]. In contrast, the intense diminution of caveolin-1 observed in smooth muscle from airway adjacent vessels in experimental guinea pigs appears to be related to the increase in proliferation. In this sense, it is known that caveolin-1 has a fundamental role in regulating the proliferation of vascular smooth muscle [42]. In mice, the absence of caveolin-1 has been shown to modify arterial filling and increase pulmonary vascular resistance [43]. To determinate the putative physiopathological effect of vascular smooth muscle hyperplasia on our experimental guinea pigs, systemic and pulmonary arterial pressures were evaluated. The experimental and control groups did not show differences in systemic or pulmonary arterial pressures $(n=4$ in control, and $n=8$ in asthma group; Figure $7 \mathrm{C}$ and D). Vascular smooth muscle hyperplasia is observed in asthma patients [44], but this hyperplasia is unrelated to pulmonary hypertension because it includes not only hyperplasia of the smooth muscle but also enhanced vascular contractility and impaired vasodilation [45].

\section{Conclusions}

Our results suggest that the development of antigeninduced airway obstruction and hyperresponsiveness is associated with caveolin-1 expression in airway smooth muscle in a guinea pig model of asthma. It appears that the model induces the development of two different phenotypes, one contractile in airway smooth muscle and the other proliferative in pulmonary vessels. In addition, although the asthma model induced a strong caveolin-1 downregulation in vascular smooth muscle accompanied by myocyte proliferation, this phenomenon did not induce pathophysiological consequences such as changes in arterial pressure.

\section{Competing interests}

The authors declare that they have no competing interests.

\section{Authors' contributions}

MAS, PRR, SSH, RL, FGA, ROZ, RJV performed the experiments and acquired data. BBP and NAB analysed the data. BBP conceived of and designed the experiments and wrote the paper. All authors read and approved the final manuscript.

\section{Acknowledgements}

Mayra Alvarez-Santos was supported for his graduate studies by the Posgrado en Ciencias Biológicas, Universidad Nacional Autónoma de México (UNAM) and CONACyT for providing a scholarship number 294207. We thank Instituto Nacional de Enfermedades Respiratorias for the economic support given to this project.

\section{Author details}

${ }^{1}$ Instituto Nacional de Enfermedades Respiratorias Ismael Cosío Villegas, Departamento de Hiperreactividad Bronquial, Calzada de Tlalpan 4502, Mexico. ${ }^{2}$ Departamento de Bioquímica, Facultad de Medicina, Universidad Nacional Autónoma de México, México, DF, Mexico. ${ }^{3}$ Departamento de Cirugía Experimental, Instituto Nacional de Enfermedades,Respiratorias Ismael Cosío Villegas, Calzada de Tlalpan 4502, Mexico. ${ }^{4}$ Molecular Physiology Unit, Instituto de Investigaciones Biomédicas, Universidad Nacional Autónoma de México, México, Mexico. ${ }^{5}$ Instituto Nacional de Ciencias Médicas y Nutrición Salvador Zubirán, Department of Nephrology, México, Mexico.

Received: 22 December 2014 Accepted: 7 March 2015

Published online: 26 March 2015

\section{References}

1. Buc M, Dzurilla M, Vrlik M, Bucova M. Immunopathogenesis of bronchial asthma. Arch Immunol Ther Exp (Warsz). 2009;57:331-44.

2. Cockcroft DW, Davis BE. Mechanisms of airway hyperresponsiveness. J Allergy Clin Immunol. 2006;118:551-9. quiz 560-551.

3. Fridolfsson HN, Roth DM, Insel PA, Patel HH: Regulation of intracellular signaling and function by caveolin. FASEB J 2014.

4. Bains SN, Tourkina E, Atkinson C, Joseph K, Tholanikunnel B, Chu HW, et al. Loss of caveolin-1 from bronchial epithelial cells and monocytes in human subjects with asthma. Allergy. 2012;67:1601-4.

5. Chen CM, Wu MY, Chou HC, Lang YD, Wang LF. Downregulation of caveolin-1 in a murine model of acute allergic airway disease. Pediatr Neonatol. 2011;52:5-10.

6. Le Saux CJ, Teeters K, Miyasato SK, Hoffmann PR, Bollt O, Douet V, et al. Down-regulation of caveolin-1, an inhibitor of transforming growth factor-beta signaling, in acute allergen-induced airway remodeling. J Biol Chem. 2008;283:5760-8.

7. Aravamudan B, Vanoosten SK, Meuchel LW, Vohra P, Thompson M, Sieck GC, et al. Caveolin-1 knockout mice exhibit airway hyperreactivity. Am J Physiol Lung Cell Mol Physiol. 2012;303:L669-681.

8. Gosens R, Stelmack GL, Bos ST, Dueck G, Mutawe MM, Schaafsma D, et al. Caveolin-1 is required for contractile phenotype expression by airway smooth muscle cells. J Cell Mol Med. 2011;15:2430-42.

9. Halayko AJ, Tran T, Gosens R. Phenotype and functional plasticity of airway smooth muscle: role of caveolae and caveolins. Proc Am Thorac Soc. 2008:5:80-8

10. Le Saux O, Teeters K, Miyasato S, Choi J, Nakamatsu G, Richardson JA, et al. The role of caveolin-1 in pulmonary matrix remodeling and mechanical properties. Am J Physiol Lung Cell Mol Physiol. 2008;295:L1007-1017. 
11. Gabehart KE, Royce SG, Maselli DJ, Miyasato SK, Davis EC, Tang ML, et al. Airway hyperresponsiveness is associated with airway remodeling but not inflammation in aging Cav1-/- mice. Respir Res. 2013;14:110.

12. Hsia BJ, Pastva AM, Giamberardino CD, Potts-Kant EN, Foster WM, Que LG, Abraham SN, Wright JR, Zaas DW: Increased Nitric Oxide Production Prevents Airway Hyperresponsiveness in Caveolin-1 Deficient Mice Following Endotoxin Exposure. J Allergy Ther 2012, Suppl 1.

13. Bergdahl A, Sward K. Caveolae-associated signalling in smooth muscle. Can J Physiol Pharmacol. 2004;82:289-99.

14. Gosens R, Mutawe M, Martin S, Basu S, Bos ST, Tran T, et al. Caveolae and caveolins in the respiratory system. Curr Mol Med. 2008;8:741-53.

15. Darby PJ, Kwan CY, Daniel EE. Caveolae from canine airway smooth muscle contain the necessary components for a role in $\mathrm{Ca}(2+)$ handling. Am J Physiol Lung Cell Mol Physiol. 2000;279:L1226-1235.

16. Gosens R, Stelmack GL, Dueck G, Mutawe MM, Hinton M, McNeill KD, et al. Caveolae facilitate muscarinic receptor-mediated intracellular Ca2+ mobilization and contraction in airway smooth muscle. Am J Physiol Lung Cell Mol Physiol. 2007;293:L1406-1418

17. Prakash YS, Thompson MA, Vaa B, Matabdin I, Peterson TE, He T, et al. Caveolins and intracellular calcium regulation in human airway smooth muscle. Am J Physiol Lung Cell Mol Physiol. 2007;293:L1118-1126.

18. Hunter I, Nixon GF. Spatial compartmentalization of tumor necrosis factor (TNF) receptor 1-dependent signaling pathways in human airway smooth muscle cells. Lipid rafts are essential for TNF-alpha-mediated activation of RhoA but dispensable for the activation of the NF-kappaB and MAPK pathways. J Biol Chem. 2006;281:34705-15.

19. Taggart MJ, Leavis $P$, Feron O, Morgan KG. Inhibition of PKCalpha and rhoA translocation in differentiated smooth muscle by a caveolin scaffolding domain peptide. Exp Cell Res. 2000;258:72-81.

20. Sathish V, Abcejo AJ, Thompson MA, Sieck GC, Prakash YS, Pabelick CM: Caveolin-1 regulation of store-operated $\mathrm{Ca} 2+$ influx in human airway smooth muscle. Eur Respir J 2012.

21. Vinten J, Johnsen AH, Roepstorff P, Harpoth J, Tranum-Jensen J. Identification of a major protein on the cytosolic face of caveolae. Biochim Biophys Acta. 2005; 1717:34-40.

22. Hansen CG, Nichols BJ. Exploring the caves: cavins, caveolins and caveolae. Trends Cell Biol. 2010;20:177-86.

23. Bazan-Perkins B, Sanchez-Guerrero E, Vargas MH, Martinez-Cordero E, Ramos-Ramirez P, Alvarez-Santos M, et al. Beta1-integrins shedding in a guinea-pig model of chronic asthma with remodelled airways. Clin Exp Allergy. 2009;39:740-51.

24. Smith N, Broadley KJ. Optimisation of the sensitisation conditions for an ovalbumin challenge model of asthma. Int Immunopharmacol. 2007;7:183-90.

25. Ricciardolo FL, Nijkamp F, De Rose V, Folkerts G. The guinea pig as an animal model for asthma. Curr Drug Targets. 2008;9:452-65.

26. Ressmeyer AR, Larsson AK, Vollmer E, Dahlen SE, Uhlig S, Martin C. Characterisation of guinea pig precision-cut lung slices: comparison with human tissues. Eur Respir J. 2006;28:603-11.

27. Ramos-Ramirez P, Campos MG, Martinez-Cordero E, Bazan-Perkins B, Garcia-Zepeda E. Antigen-induced airway hyperresponsiveness in absence of broncho-obstruction in sensitized guinea pigs. Exp Lung Res. 2013;39:136-45.

28. Hamelmann E, Schwarze J, Takeda K, Oshiba A, Larsen GL, Irvin CG, et al. Noninvasive measurement of airway responsiveness in allergic mice using barometric plethysmography. Am J Respir Crit Care Med. 1997;156:766-75.

29. Lecoeur H, Ledru E, Gougeon ML. A cytofluorometric method for the simultaneous detection of both intracellular and surface antigens of apoptotic peripheral lymphocytes. J Immunol Methods. 1998;217:11-26.

30. Sambrook J, Russell DW, Sambrook J. The condensed protocols from Molecular cloning : a laboratory manual. Cold Spring Harbor, N.Y.: Cold Spring Harbor Laboratory Press; 2006.

31. Bobadilla NA, Herrera JP, Merino A, Gamba G. Semi-quantitative PCR: a tool to study low abundance messages in the kidney. Arch Med Res. 1997;28:55-60.

32. Canning BJ, Chou Y. Using guinea pigs in studies relevant to asthma and COPD. Pulm Pharmacol Ther. 2008;21:702-20.

33. Woodruff PG, Modrek B, Choy DF, Jia G, Abbas AR, Ellwanger A, et al. T-helper type 2-driven inflammation defines major subphenotypes of asthma. Am J Respir Crit Care Med. 2009;180:388-95.

34. Gabella G. Quantitative morphological study of smooth muscle cells of the guinea-pig taenia coli. Cell Tissue Res. 1976;170:161-86.
35. Sharma P, Ghavami S, Stelmack GL, McNeill KD, Mutawe MM, Klonisch T, et al. beta-Dystroglycan binds caveolin-1 in smooth muscle: a functional role in caveolae distribution and Ca2+ release. J Cell Sci. 2010;123:3061-70.

36. Brightling C, Berry M, Amrani Y. Targeting TNF-alpha: a novel therapeutic approach for asthma. J Allergy Clin Immunol. 2008;121:5-10. quiz 11-12.

37. Sathish V, Abcejo AJ, VanOosten SK, Thompson MA, Prakash YS, Pabelick CM. Caveolin-1 in cytokine-induced enhancement of intracellular $\mathrm{Ca}(2+)$ in human airway smooth muscle. Am J Physiol Lung Cell Mol Physiol. 2011;301:L607-614.

38. Sathish V, Yang B, Meuchel LW, VanOosten SK, Ryu AJ, Thompson MA, et al. Caveolin-1 and force regulation in porcine airway smooth muscle. Am J Physiol Lung Cell Mol Physiol. 2011;300:L920-929.

39. Sathish V, Thompson MA, Sinha S, Sieck GC, Prakash YS, Pabelick CM. Inflammation, caveolae and CD38-mediated calcium regulation in human airway smooth muscle. Biochim Biophys Acta. 1843;2014:346-51.

40. Gosens R, Dueck G, Gerthoffer WT, Unruh H, Zaagsma J, Meurs H, et al. p42/p44 MAP kinase activation is localized to caveolae-free membrane domains in airway smooth muscle. Am J Physiol Lung Cell Mol Physiol. 2007;292:L1163-1172.

41. Jin Y, Lee SJ, Minshall RD, Choi AM. Caveolin-1: a critical regulator of lung injury. Am J Physiol Lung Cell Mol Physiol. 2011;300:L151-160.

42. Sedding DG, Braun-Dullaeus RC. Caveolin-1: dual role for proliferation of vascular smooth muscle cells. Trends Cardiovasc Med. 2006;16:50-5.

43. Maniatis NA, Shinin V, Schraufnagel DE, Okada S, Vogel SM, Malik AB, et al. Increased pulmonary vascular resistance and defective pulmonary artery filling in caveolin-1-/- mice. Am J Physiol Lung Cell Mol Physiol. 2008;294:L865-873.

44. Harkness LM, Kanabar V, Sharma HS, Westergren-Thorsson G, LarssonCallerfelt AK: Pulmonary vascular changes in asthma and COPD. Pulm Pharmacol Ther 2014.

45. Yildiz P. Molecular mechanisms of pulmonary hypertension. Clin Chim Acta. 2009;403:9-16.

\section{Submit your next manuscript to BioMed Central and take full advantage of:}

- Convenient online submission

- Thorough peer review

- No space constraints or color figure charges

- Immediate publication on acceptance

- Inclusion in PubMed, CAS, Scopus and Google Scholar

- Research which is freely available for redistribution 